\title{
ASYMPTOTICS OF THE FILTRATION PROBLEM WITH ALMOST CONSTANT COEFFICIENTS
}

\author{
Liudmila I. Kuzmina ${ }^{1}$, Yuri V. Osipov ${ }^{2}$ \\ ${ }^{1}$ National Research University Higher School of Economics, Moscow, RUSSIA \\ ${ }^{2}$ Moscow State University of Civil Engineering, Moscow, RUSSIA
}

\begin{abstract}
During the construction of hydraulic and underground structures, a grout solution is pumped into the ground to create waterproof partitions. The liquid grout is filtered in the porous rock and clogs the pores when hardened. The mathematical model of deep bed filtration describes the transfer of suspension particles and colloids by a fluid flow through the pores of a rock. For a one-dimensional filtration problem in a homogeneous porous medium with almost constant coefficients, an asymptotic solution is constructed. The asymptotics is compared with the numerical solution.
\end{abstract}

Keywords: deep bed filtration, suspensions and colloids, porous medium, suspended and retained particles, asymptotic solution.

\section{АСИМПТОТИКА ЗАДАЧИ ФИЛЬТРАЦИИ С ПОЧТИ ПОСТОЯННЫМИ КОЭФФИЦИЕНТАМИ}

\footnotetext{
Л.И. Кузьмина ${ }^{1}$, Ю.В. Осипов ${ }^{2}$

${ }^{1}$ Национальный исследовательский университет «Высшая школа экономики», г. Москва, РОССИЯ

2 Национальный исследовательский Московский государственный строительный университет, г. Москва, РОССИЯ

\begin{abstract}
Аннотация: При строительстве гидротехнических и подземных сооружений для создания водонепроницаемых перегородок в грунт закачивается раствор укрепителя. Жидкий укрепитель фильтруется в пористой породе и при застывании закупоривает поры. Математическая модель фильтрации описывает перенос жидкостью частиц суспензий и коллоидов через поры горной породы. Для одномерной задачи фильтрации в однородной пористой среде с мало меняющимися коэффициентами построено асимптотическое решение. Асимптотика сравнивается с численным решением.
\end{abstract}

Ключевые слова: фильтрация, суспензии и коллоиды, пористая среда, взвешенные и осажденные частицы, асимптотическое решение.

\section{INTRODUCTION}

Filtration of suspensions and colloids in porous media occurs in many natural and technological processes: the spread of microorganisms in the aquatic environment, filtration of water in rocks, treatment of industrial and domestic wastewater, a decrease in oil production due to the deposition of small particles entrained in water near the well, and much more [1-3]. During the construction of tunnels and underground storage facilities for hazardous toxic and radioactive waste, a liquid grout is pumped into the rock under pressure to create watertight walls. The grout filters in the porous soil and clogs the pores after solidification [4].

The transport of micro- and nanoparticles in a porous medium is accompanied by the retention of particles and the formation of a deposit. Various retention mechanisms of particles carried by a fluid flow in a porous medium of complex structure are determined by electric, gravitational and hydrodynamic forces [5-7]. Filtration models take into account either a single prevailing retention mechanism, or several mechanisms acting simultaneously $[8,9]$. 
The mathematical model of deep bed filtration includes the equation for the balance of the masses of suspended and retained particles and the kinetic equation of deposit growth, which form a quasilinear hyperbolic system of the first order partial differential equations [10]. To solve filtration problems, both numerical and analytical methods are used [11-16]. Analytical methods allow to obtain exact and asymptotic solutions and their dependence on parameters. This makes it possible to fine-tune experiments and to solve inverse filtration problems [17-19].

The classical filtration model assumes that the properties of the porous medium do not change with the formation of deposit. More sophisticated models take into account the dependence of porosity and permissible flow on the concentration of deposit [20]. In these models, it is assumed that a suspension or colloidal solution of constant volume concentration is injected at the inlet of a porous medium.

We consider a one-dimensional model for deep bed filtration of particles carried by a fluid flow in a homogeneous porous medium. It is assumed that the carrier fluid is incompressible; at the porous medium inlet the suspended particles concentration is variable. Experiments show that the coefficients of the filtration equations depending on the retained concentration do not change much. This allows us to construct an asymptotic solution to the filtration problem. The asymptotics is compared with the numerical solution.

\section{MATHEMATICAL MODEL}

In the domain $\Omega=\{0 \leq x \leq 1, t \geq 0\}$, consider the system of first-order differential equations

$$
\begin{gathered}
\frac{\partial}{\partial t}(g(S) C)+\frac{\partial}{\partial x}(f(S) C)+\frac{\partial S}{\partial t}=0, \\
\frac{\partial S}{\partial t}=\Lambda(S) C .
\end{gathered}
$$

Here the blocking filtration function $\Lambda(S)$ is smooth and positive at $0 \leq S<S_{m}, S_{m}>0 ; \Lambda(S)$
$=0$ at $S \geq S$; the functions $g(S)$ and $f(S)$ are positive at $0 \leq S \leq S_{m} ; C(x, t), S(x, t)$ - the unknown volumetric concentrations of suspended and retained particles [21].

For the uniqueness of the solution to the system (1), (2), the initial and boundary conditions are set

$$
\begin{gathered}
\left.C\right|_{x=0}=p(t), \quad p(t)>0, \\
\left.C\right|_{t=0}=0,\left.\quad S\right|_{t=0}=0 .
\end{gathered}
$$

Condition (3) means that a suspension of variable concentration is injected at the inlet of the porous medium; by condition (4), at the initial moment of time, the porous medium does not contain any suspended and retained particles. The concentrations front of the suspended and retained particles given by the formula $x=v t, v=f(0) / g(0)$ moves with a speed $v$ from the inlet to the outlet of the porous medium. Ahead of the front in the domain $\Omega_{0}=\{0 \leq x \leq 1, t<x\}$, the solution is zero; behind the front in the domain $\Omega_{1}=\{0 \leq x \leq 1, t$ $>x\}$, the decision is positive. Since conditions (3) and (4) do not matched at the origin, the solution $C$ is discontinuous at the concentration front; the solution $S$ is continuous in the whole domain $\Omega$. Consider the condition on the concentrations front

$$
\left.S\right|_{x=v t}=0
$$

In the domain $\bar{\Omega}_{1}$, the solution to problem (1)-(4) coincides with the solution to the Goursat problem (1)-(3), (5).

In characteristic variables $\tau=t-x / v, y=x$, the Goursat problem takes the form

$$
\begin{gathered}
\frac{\partial}{\partial \tau}(g(S) C)-\frac{1}{v} \frac{\partial}{\partial \tau}(f(S) C)+ \\
+\frac{\partial}{\partial y}(f(S) C)+\frac{\partial S}{\partial \tau}=0 \\
\frac{\partial S}{\partial \tau}=\Lambda(S) C .
\end{gathered}
$$


Conditions (3) and (5) take the form

$$
\begin{gathered}
\left.C\right|_{y=0}=p(\tau), \\
\left.S\right|_{\tau=0}=0 .
\end{gathered}
$$

\section{ASYMPTOTICS FOR ALMOST CONSTANT COEFFICIENTS}

Assume that the coefficients of equations (1), (2) admit expansions

$$
\begin{aligned}
& g(S)=g_{0}+\varepsilon g_{1} S+\ldots, \\
& f(S)=f_{0}+\varepsilon f_{1} S+\ldots \\
& \Lambda(S)=\Lambda_{0}+\varepsilon \Lambda_{1} S+\ldots .
\end{aligned}
$$

Here $\varepsilon$ is a small positive parameter.

The solution to the system (6), (7) is obtained in the form $[22,23]$

$$
\begin{aligned}
& S(y, \tau)=s_{0}(y, \tau)+\varepsilon s_{1}(y, \tau)+\ldots \\
& C(y, \tau)=c_{0}(y, \tau)+\varepsilon c_{1}(y, \tau)+\ldots
\end{aligned}
$$

Substitute the expansions (10), (11) into the equations (6), (7) and equate the terms at the same powers of $\varepsilon$. We obtain a recurrent system of differential equations

$$
\begin{aligned}
& f_{0} \frac{\partial c_{0}}{\partial y}+\Lambda_{0} c_{0}=0, \quad \text { (12) } \\
& \frac{\partial s_{0}}{\partial \tau}=\Lambda_{0} c_{0}, \\
& \begin{array}{l}
\text { Substituting the solutions (18)-(20) } \\
\text { expansions (11) and passing to the } \\
\text { coordinates, we obtain an asymptotic } \\
\text { the problem (1)-(4) in the domain } \bar{\Omega}_{1}
\end{array} \\
& +f_{0} \frac{\partial c_{1}}{\partial y}+\Lambda_{0} c_{1}+f_{1} \frac{\partial s_{0}}{\partial y} c_{0}+\Lambda_{1} s_{0} c_{0}=0, \\
& S(x, t)=\Lambda_{0} P(t-x / v) e^{-A x}\left(1+\varepsilon\left((B+0.5 P(t-x / v))\left(D\left(e^{-A x}-1\right)+\Lambda_{1} e^{-A x}\right)\right)\right), \\
& C(x, t)=p(t-x / v) e^{-A x}\left(1+\varepsilon(B+D P(t-x / v))\left(e^{-A x}-1\right)\right) .
\end{aligned}
$$

$$
\frac{\partial s_{0}}{\partial \tau}=\Lambda_{0} c_{1}+\Lambda_{1} s_{0} c_{0}
$$

Conditions for the equations (12)-(15) follow from (8) and (9)

$$
\begin{gathered}
\left.c_{0}\right|_{y=0}=p(\tau),\left.c_{1}\right|_{y=0}=0 . \\
\left.s_{0}\right|_{\tau=0}=0,\left.s_{1}\right|_{\tau=0}=0 .
\end{gathered}
$$

Solution to the system (12)-(15) with the conditions (16), (17)

$$
\begin{gathered}
c_{0}=p(\tau) e^{-A y}, s_{0}=\Lambda_{0} P(\tau) e^{-A y}, \\
c_{1}=p(\tau)(B+D P(\tau)) e^{-A y}\left(e^{-A y}-1\right), \\
s_{1}=\Lambda_{0}\left(B p_{1}(\tau)+0.5 D P^{2}(\tau)\right) e^{-A y} \\
\cdot\left(e^{-A y}-1\right)+0.5 \Lambda_{0} \Lambda_{1} P^{2}(\tau) e^{-2 A y}
\end{gathered}
$$

Here

$$
\begin{aligned}
& A=\frac{\Lambda_{0}}{f_{0}}, P(\tau)=\int_{0}^{\tau} p(z) d z, \\
& B=g_{1}-f_{1} / \nu, D=\Lambda_{1}-\frac{f_{1}}{f_{0}} \Lambda_{0} .
\end{aligned}
$$

Substituting the solutions (18)-(20) into the expansions (11) and passing to the Cartesian coordinates, we obtain an asymptotic solution to 


\section{RESULTS OF NUMERICAL MODELLING}

The numerical calculation was carried out for the coefficients of equations (1), (2) obtained from the results of experiments with particles of a suspension with a radius of 2.179 microns in the laboratory of the University of Adelaide, Australia [24]

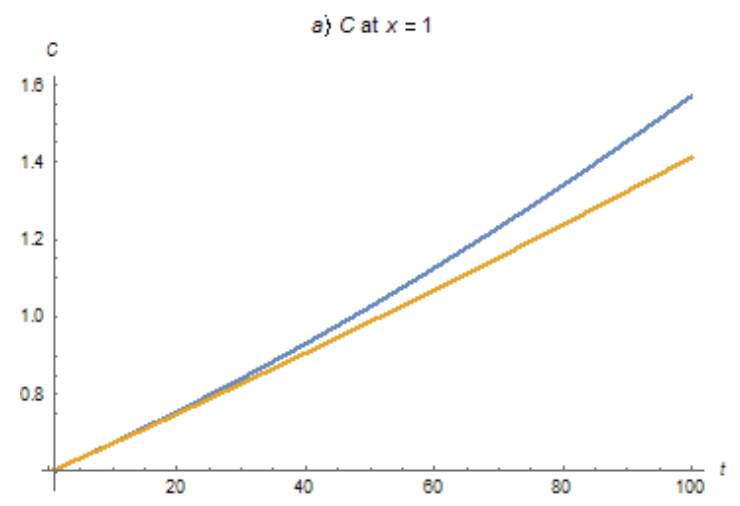

Figure 1. Concentrations at the porous medium outlet $x=1$ a) suspended $C(1, t) ; b)$ retained $S(1, t)$.
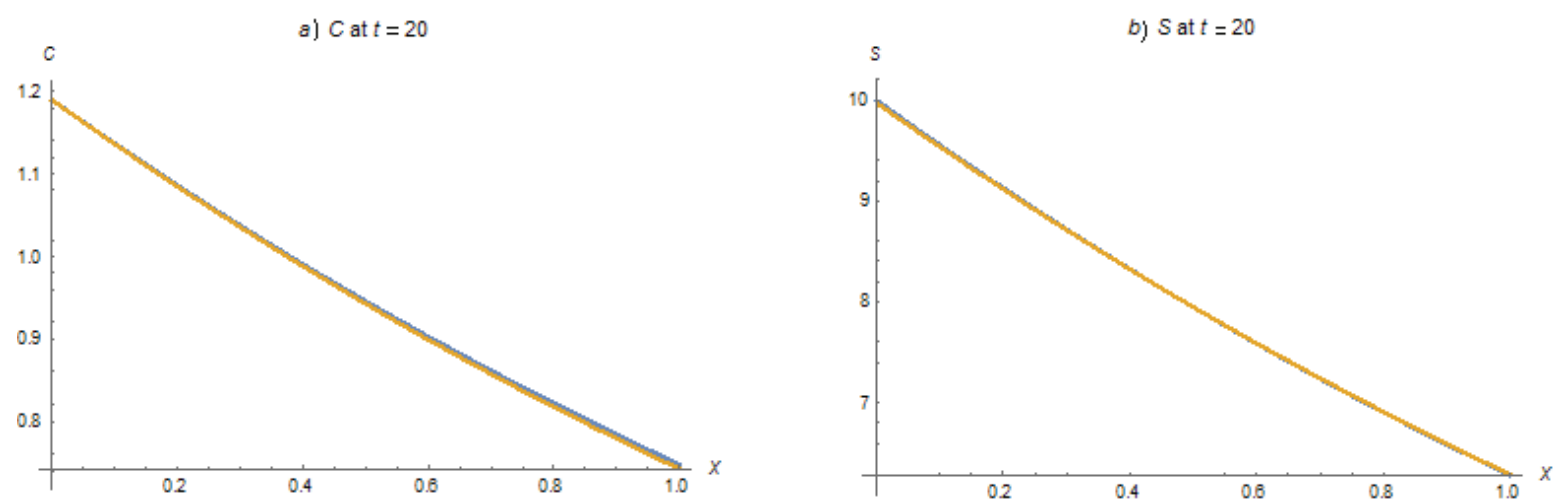

Figure 2. Concentrations at fixed time $t=20$ a) suspended $C(x, 20)$; b) retained $S(x, 20)$.
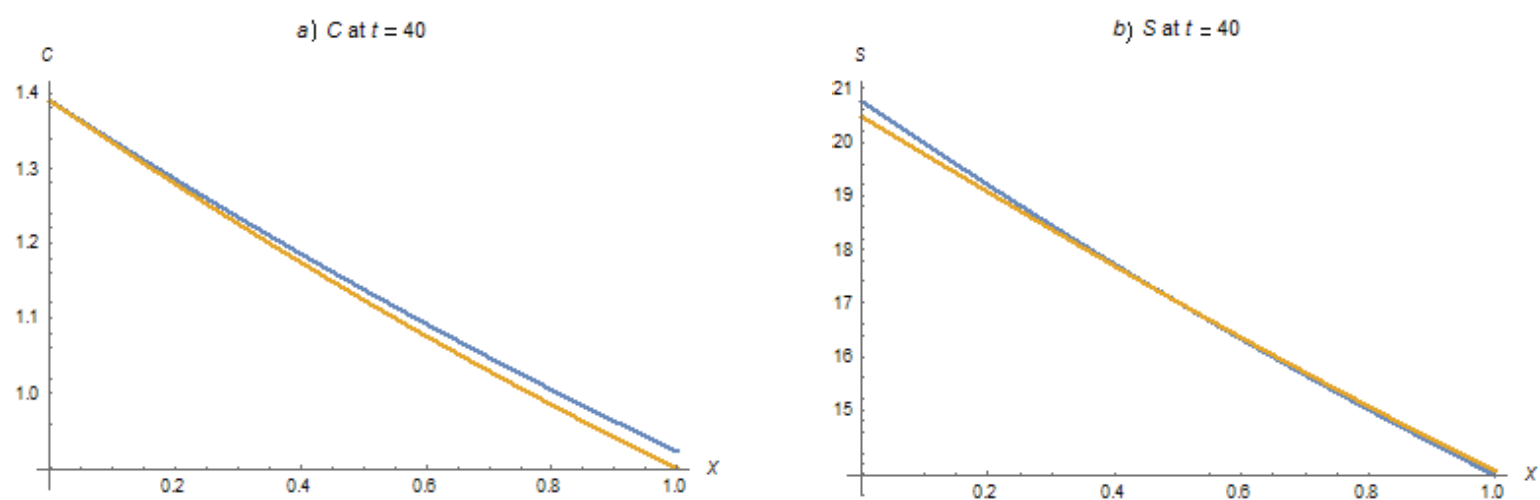

Figure 3. Concentrations at fixed time $t=40$ a) suspended $C(x, 40)$; b) retained $S(x, 40)$. 

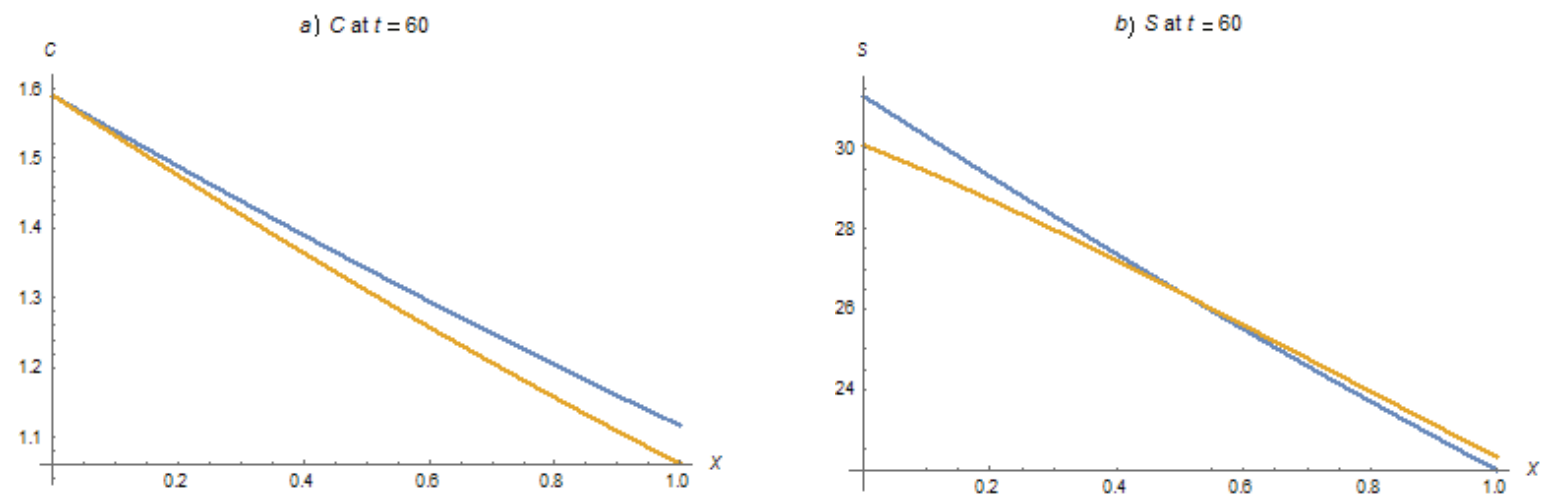

Figure 4. Concentrations at fixed time $t=60$ a) suspended $C(x, 60)$; b) retained $S(x, 60)$.

At the porous medium outlet $x=1$, the relative error of the asymptotics increases with time. For the suspended and retained particles concentrations, the error reaches $2.5 \%$ and $0.1 \%$ at $t=40$, $1 \%$ and $5 \%$ at $t=60,5 \%$ and $10 \%$ at $t=100$, respectively. For a fixed time, the relative error of the asymptotics throughout the whole porous medium does not exceed $1 \%$ at $t=20,2 \%$ at $t=$ 40 , and $4 \%$ at $t=60$ for both types of particles concentrations.

\section{CONCLUSIONS}

The study of the mathematical model of deep bed filtration of suspensions and colloids in a porous medium allows us to draw the following conclusions.

- An asymptotic solution to the filtration problem is constructed.

- The main term of the asymptotics coincides with the exact solution of the problem with constant coefficients.

- The asymptotics is close to the numerical solution.

- The asymptotic solution depending on the model parameters can be used to fine-tune laboratory experiments and to solve the inverse filtration problem.

\section{REFERENCES}

1. Khilar K.C., Fogler H.S. Migrations of Fines in Porous Media, Kluwer Academic, Dordrecht, The Netherlands, 1998.

2. Mikhailov D., Zhvick V., Ryzhikov N, Shako V. Modeling of Rock Permeability Damage and Repairing Dynamics Due to Invasion and Removal of Particulate from Drilling Fluids. // Transport in Porous Media, 2018, vol. 121, pp. 37-67.

3. Lufingo M., Ndé-Tchoupé A.I., Hu R., Njau K.N., Noubactep C. A novel and facile method to characterize the suitability of metallic iron for water treatment. // Water, 2019, vol. 11(12), 2465.

4. Strømsvik H. The significance of hydraulic jacking for grout consumption during high pressure pre-grouting in Norwegian tunnelling. // Tunnelling and Underground Space Technology, 2019, vol. 90, pp. 357368.

5. Bradford S.A., Yates S.R., Bettahar M., Simunek J. Physical factors affecting the transport and fate of colloids in saturated porous media. // Water Resources Research, 2002, vol. 38(12), 1327.

6. Mays D.C., Hunt J.R. Hydrodynamic and chemical factors in clogging by montmorillonite in porous media. // Environmental Science and Technology, 2007, vol. 41, pp. 5666-5671. 
7. Chrysikopoulos C.V., Syngouna V.I. Effect of gravity on colloid transport through watersaturated columns packed with glass beads: modeling and experiments. // Environmental Science and Technology, 2014, vol. 48, pp. 6805-6813.

8. Kuzmina L., Osipov Y. Deep bed filtration with multiple pore-blocking mechanisms. // MATEC Web of Conferences, 2018, vol. 196, 04003.

9. Zhang H., Malgaresi G.V.C., Bedrikovetsky P. Exact solutions for suspension-colloidal transport with multiple capture mechanisms. // International Journal of Non-Linear Mechanics, 2018, vol. 105, pp. 27-42.

10. Vyazmina E.A., Bedrikovetskii P.G., Polyanin A.D. New classes of exact solutions to nonlinear sets of equations in the theory of filtration and convective mass transfer. // Theoretical Foundations of Chemical Engineering, 2007, vol. 41(5), pp. 556-564.

11. Galaguz Y., Safina G. Calculation of colloids filtration in a porous medium. // IOP Conference Series: Materials Science and Engineering, 2018, vol. 365, 042005.

12. Safina G. Numerical solution of filtration in porous rock. // E3S Web of Conferences, 2019, vol. 97, 05016.

13. Kuzmina L.I., Osipov Y.V., Zheglova Y.G. Analytical model for deep bed filtration with multiple mechanisms of particle capture. // International Journal of Non-linear Mechanics, 2018, vol. 105, pp. 242-248.

14. Kuzmina L.I., Nazaikinskii V.E. Osipov Y.V. On a Deep Bed Filtration Problem with Finite Blocking Time. // Russian Journal of Mathematical Physics, 2019, vol. 26(1), pp. 130-134.

15. Galaguz Yu.P., Kuzmina L.I., Osipov Yu.V. Problem of Deep Bed Filtration in a Porous Medium with the Initial Deposit. // Fluid Dynamics, 2019, vol. 54(1), pp. 85-97.
16. Kuzmina L.I., Osipov Y.V., Gorbunova T.N. Asymptotics for filtration of polydisperse suspension with small impurities. // Applied Mathematics and Mechanics (English Edition), 2021, vol. 42(1), 109-126.

17. Yang S., Russell T., Badalyan A., Schacht U., Woolley M., Bedrikovetsky P. Characterisation of fines migration system using laboratory pressure measurements. // Journal of Natural Gas Science and Engineering, 2019, vol. 65, pp. 108-124.

18. Kuzmina L.I., Osipov Yu.V. Inverse problem of filtering the suspension in porous media. // International Journal for Computational Civil and Structural Engineering, 2015, vol. 11(1), pp. 34-41.

19. Kuzmina L.I., Osipov Yu.V. Determining the Lengmur coefficient of the filtration problem. // International Journal for Computational Civil and Structural Engineering, 2020, vol. 16(4), pp. 48-54.

20. Bedrikovetsky P. Upscaling of stochastic micro model for suspension transport in porous media. // Transport in Porous Media, 2008, vol. 75(3), pp. 335-369.

21. Herzig J.P., Leclerc D.M., Le Goff P. Flow of Suspensions Through Porous Media Application to Deep Filtration. // Journal of Industrial \& Engineering Chemistry, 1970, 62(8), pp. 8-35.

22. Olver F.W.J. Introduction to Asymptotics and Special Functions, Academic Press, New York, 1974.

23. Maslov V.P., Arnold V.I., Buslaev V.S. Theory of perturbations and asymptotic methods, Dunod, Paris, 1972.

24. You Z., Osipov Y., Bedrikovetsky P., Kuzmina L. Asymptotic model for deep bed filtration. // Chemical Engineering Journal, 2014, vol. 258, pp. 374-385. 
Liudmila I. Kuzmina, Candidate of Physical and Mathematical Sciences, Associate Professor, Department of Applied Mathematics, National Research University Higher School of Economics, 101000, Russia, Moscow, Myasnitskaya st., 20, tel. +7(495) $7729590 * 15219$, e-mail: 1kuzmina@hse.ru.

Yuri V. Osipov, Candidate of Physical and Mathematical Sciences, Associate Professor, Department of Applied Mathematics, Moscow State University of Civil Engineering, 129337, Russia, Moscow, Yaroslavskoe Shosse, 26, tel. +7(499)1835994, e-mail: yuri-osipov@mail.ru.
Кузьмина Людмила Ивановна, доцент, кандидат физико-математических наук, Департамент прикладной математики, Национальный исследовательский университет «Высшая школа экономики»; 101000, г. Москва, ул. Мясницкая, д. 20, тел. +7(495) $7729590 * 15219$; e-mail: 1kuzmina@hse.ru.

Осипов Юрий Викторович, доцент, кандидат физико-математических наук, кафедра прикладной математики Национального исследовательского Московского государственного строительного университета; 129337, Россия, г. Москва, Ярославское шоссе, д. 26; тел. +7(499)1835994; e-mail: yuri-osipov@mail.ru. 